\title{
OPEN Synthesis of short-range ordered aluminosilicates at ambient conditions
}

\author{
Katharina R. Lenhardt ${ }^{1 \bowtie}$, Hergen Breitzke², Gerd Buntkowsky², Erik Reimhult ${ }^{3}$, \\ Max Willinger ${ }^{3}$ \& Thilo Rennert ${ }^{1}$
}

We report here on structure-related aggregation effects of short-range ordered aluminosilicates (SROAS) that have to be considered in the development of synthesis protocols and may be relevant for the properties of SROAS in the environment. We synthesized SROAS of variable composition by neutralizing aqueous aluminium chloride with sodium orthosilicate at ambient temperature and pressure. We determined elemental composition, visualized morphology by microscopic techniques, and resolved mineral structure by solid-state ${ }^{29} \mathrm{Si}$ and ${ }^{27} \mathrm{Al}$ nuclear magnetic resonance and Fouriertransform infrared spectroscopy. Nitrogen sorption revealed substantial surface loss of Al-rich SROAS that resembled proto-imogolite formed in soils and sediments due to aggregation upon freezing. The effect was less pronounced in Si-rich SROAS, indicating a structure-dependent effect on spatial arrangement of mass at the submicron scale. Cryomilling efficiently fractured aggregates but did not change the magnitude of specific surface area. Since accessibility of surface functional groups is a prerequisite for sequestration of substances, elucidating physical and chemical processes of aggregation as a function of composition and crystallinity may improve our understanding of the reactivity of SROAS in the environment.

Sufficient release of aluminium (Al) and silicon (Si) by weathering of siliceous parent material facilitates precipitation of hydrous, short-range ordered aluminosilicates (SROAS). Accumulation of these phases results in coatings and alteromorphs in volcanic rocks ${ }^{1,2}$, clay-sized particles in andic soils ${ }^{3-5}$ or stream deposits from waters passing through extrusive rocks ${ }^{6,7}$. Formation of SROAS is not limited to volcanic parent material, but also takes place along pedogenetic transformation of more crystalline siliceous rocks ${ }^{8-10}$. The presence of SROAS imposes peculiar properties on soil material with respect to retention of plant nutrients ${ }^{11}$, pollutants ${ }^{12}$ and degradation products of soil organic matter $(\mathrm{SOM})^{13}$, which promotes carbon sequestration in andic soils ${ }^{14}$. Efficient sorption of various compounds is ascribed to large surface areas and the microporous nature of SROAS, including the presence of reactive functional groups ${ }^{15}$. To investigate molecular interactions in detail, preparation of mineral analogues by synthesis is a common procedure in environmental research, since physical separation of SROAS from natural samples may not be sufficient with respect to mass or selectivity. For instance, synthetic SROAS were used to study their interactions with extracellular enzymes in soils ${ }^{16,17}$, adsorption mechanisms of potentially toxic metals ${ }^{18,19}$, and retention of organic and inorganic anions ${ }^{20}$.

Surface properties of SROAS are fundamentally related to their structure as it governs the quantity, reactivity and arrangement of functional groups. Microscopic techniques revealed that SROAS can develop distinct morphologies at the nanoscale, such as tubes and hollow spheres ${ }^{21,22}$. Tube-shaped SROAS have a well-defined structure and are termed imogolite ${ }^{23}$. Imogolite occurs as bundles of tubes with external diameters of approximately $2 \mathrm{~nm}$ that can reach lengths of several micrometres by anisotropic crystallization ${ }^{8,21}$. Its structure is built up by a dioctahedral $\mathrm{Al}$ sheet constituting the outer surface, with single Si tetrahedra linked to three Al octahedra inside the tube ${ }^{23}$. This specific configuration of $\mathrm{Si}$ can be detected by solid-state ${ }^{29} \mathrm{Si}$ nuclear magnetic resonance (NMR) spectroscopy, henceforth denoted as $\mathrm{Q}^{0}(3 \mathrm{Al})^{24}$. Because of its morphology, imogolite offers porosity provided by pores with diameters $<1 \mathrm{~nm}^{25}$. Allophane is a generic term, referring to structurally less defined SROAS with variable chemical compositions that are classified according to their Al:Si ratio in the first instance ${ }^{26}$. Particularly Al-rich compounds ( $\mathrm{Al}: \mathrm{Si} \geq 2)$ may contain $\mathrm{Si}$ in $\mathrm{Q}^{0}(3 \mathrm{Al})$ coordination and may be termed proto-imogolite,

${ }^{1}$ Fachgebiet Bodenchemie mit Pedologie, Institut für Bodenkunde und Standortslehre, Universität Hohenheim, Emil-Wolff-Str. 27, 70599 Stuttgart, Germany. ${ }^{2}$ Eduard-Zintl-Institut für Anorganische und Physikalische Chemie, Technische Universität Darmstadt, Alarich-Weiss-Str. 8, 64287 Darmstadt, Germany. ${ }^{3}$ Institut für Biologisch Inspirierte Materialien, Universität für Bodenkultur Wien, Muthgasse 11/II, 1190 Wien, Austria. ${ }^{\square}$ email: katharina.lenhardt@uni-hohenheim.de 


\begin{tabular}{|c|c|c|c|c|c|c|c|c|c|c|c|c|}
\hline \multirow[b]{2}{*}{ Initial Al:Si } & \multirow[b]{2}{*}{$\mathrm{Al}: \mathrm{Si}$} & $\mathrm{Al}$ & $\mathrm{Si}$ & $\mathrm{Na}$ & \multirow{2}{*}{$\begin{array}{l}\mathrm{Si} \text { in } \mathrm{Q}^{0}(3 \mathrm{Al}) \\
(\% \mathrm{Si})\end{array}$} & ${ }^{\mathrm{IV}} \mathrm{Al}$ & $\mathrm{v}_{\mathrm{Al}}$ & ${ }^{{ }^{\mathrm{VI}}} \mathbf{A l}$ & \multirow{2}{*}{$\begin{array}{l}\text { SSA } \\
\left(\mathrm{m}^{2} \mathrm{~g}^{-1}\right)\end{array}$} & $\mathbf{V}_{\mathrm{T}}$ & $\mathrm{V}_{2-10}$ & $V_{10-50}$ \\
\hline & & \multicolumn{3}{|c|}{$\left(\mathrm{mg} \mathrm{g}^{-1}\right)$} & & \multicolumn{3}{|c|}{$(\% \mathrm{Al})$} & & \multicolumn{3}{|c|}{$\left(\mathrm{mm}^{3} \mathrm{~g}^{-1}\right)$} \\
\hline 1 & 1.4 & 200.9 & \begin{tabular}{|l|}
146.3 \\
\end{tabular} & 23.1 & 9 & 29 & 5 & 66 & 295.5 & & & \\
\hline \multicolumn{2}{|l|}{ Cryomilled } & & & & & & & & 274.2 & 943 & 167 & 617 \\
\hline 1.5 & 2.1 & 245.2 & 122 & 1.8 & 38 & 13 & 6 & 80 & 25.6 & & & \\
\hline \multicolumn{2}{|l|}{ Cryomilled } & & & & & & & & 43.2 & 125 & 47 & 32 \\
\hline 2 & 2.6 & 250.1 & 100.7 & 0.3 & 48 & 9 & 6 & 85 & 0.7 & & & \\
\hline \multicolumn{2}{|l|}{ Cryomilled } & & & & 44 & 7 & 6 & 87 & 6.9 & 58 & 3 & 20 \\
\hline
\end{tabular}

Table 1. Selected chemical and physical properties of synthesized short-range ordered aluminosilicates. Proportion of Si nuclei in imogolite-like coordination $\left(\mathrm{Q}^{0}(3 \mathrm{Al})\right)$ and $\mathrm{Al}$ nuclei in tedrahedral $\left(\mathrm{Al}^{\mathrm{IV}}\right)$, pentahedral $\left(\mathrm{Al}^{\mathrm{V}}\right)$ and octahedral $\left(\mathrm{Al}^{\mathrm{VI}}\right)$ coordination was quantified by solid-state nuclear magnetic resonance spectroscopy. Specific surface area (SSA), total pore volume $\left(\mathrm{V}_{\mathrm{T}}\right)$ and pore volume of pores with diameters from 2-10 $\mathrm{nm}\left(\mathrm{V}_{2-10}\right)$ and $10-50 \mathrm{~nm}\left(\mathrm{~V}_{10-50}\right)$ was derived from nitrogen sorption analysis.

implying their function as precursors of more ordered phases ${ }^{26}$. As single hydroxyl groups coordinated to $\mathrm{Al}$ nuclei at defect sites are more reactive than bridging hydroxyls, adsorption capacity by ligand exchange decreases with crystallinity ${ }^{27,28}$. Given a sufficient $\mathrm{Si}$ supply, the Al:Si ratio decreases close to 1 , and the atomic arrangement is more similar to tectosilicates, including $\mathrm{Al}$ in tetrahedral coordination $\left(\mathrm{Al}^{\mathrm{IV}}\right)^{29}$. As a result, particles exert permanent negative charge and exhibit fewer sites prone to ligand exchange due to a larger contribution of silanol groups ${ }^{27,30}$. Structural models that assume primary particles of both Al-rich and Si-rich SROAS to be hollow spheres have been proposed ${ }^{31,32}$, but have seldom been unambiguously verified in natural and synthetic samples. As crystallisation and assembly of precursors are likely inhibited in soil environments, respective SROAS may rather be perceived as fragments and poorly defined precursors of more ordered varieties ${ }^{33}$.

We aimed at synthesizing compounds that mimic pristine surfaces of SROAS forming at the initial stages of weathering. We thus employed ambient temperature and pressure conditions. Since organic species interfere with precipitation processes ${ }^{34}$ and may remain in the precipitate, we performed synthesis in aqueous media from inorganic salts of weakly complexing counterions. We achieved precipitation of SROAS by neutralizing an acid Al chloride solution with an alkaline sodium $(\mathrm{Na})$ orthosilicate solution ${ }^{35,36}$. To obtain precipitates with different $\mathrm{Al}: \mathrm{Si}$ ratios, we varied the input of Si to give molar concentration ratios of $1,1.5$ and 2 . We used a monomeric Si source to favour the formation of $\mathrm{Si}$ in $\mathrm{Q}^{0}(3 \mathrm{Al})$ coordination and to minimize the inheritance of amorphous silica $\left(\mathrm{SiO}_{2(\mathrm{am})}\right)$, but worked at decimolar concentrations, potentially enabling its formation. We report here on the structure of synthesized SROAS, studied by X-ray diffractometry (XRD), Fourier-transform infrared (FTIR) and solid-state ${ }^{27} \mathrm{Al}$ and ${ }^{29} \mathrm{Si} \mathrm{NMR}$ spectroscopy, and its consequences on specific surface area (SSA) of dry solids because we consider them relevant for future syntheses and possibly the behaviour of similar minerals in soils and sediments. Furthermore, we describe the effects of cryomilling on the physical and structural properties of SROAS.

\section{Results and discussion}

Morphology and composition of SROAS. Elemental analysis of SROAS revealed that an increase in $\mathrm{Si}$ supply successfully led to advanced $\mathrm{Si}$ incorporation into the solids, resulting in Al:Si ratios of 2.6, 2.1 and 1.4 in the precipitates (Table 1). Silicon incorporation into the solid was accompanied by retention of $\mathrm{Na}$, as observed by Na contents of $0.3,1.8$, and $23.1 \mathrm{mg} \mathrm{g}^{-1}$ with decreasing Al:Si ratios. This points to different amounts of negatively charged sites to be balanced by Na. In the following, we will refer to SROAS according to the classification in Al-rich $(\mathrm{Al}: \mathrm{Si} \geq 2)$ and $\mathrm{Si}$-rich $(\mathrm{Al}: \mathrm{Si} \leq 2)^{26}$, giving the $\mathrm{Al}: \mathrm{Si}$ ratio in parentheses to identify an Al-rich compound. All solids exhibited larger Al:Si ratios than those originally employed in synthesis batches, evidencing preferential loss of Si during dialysis. Relative to the amount of Si expected with complete incorporation into the solid and calculated from $\mathrm{Al}$ content and initial $\mathrm{Al}: \mathrm{Si}$ ratios, the amount of $\mathrm{Si}$ in the precipitates was lower by

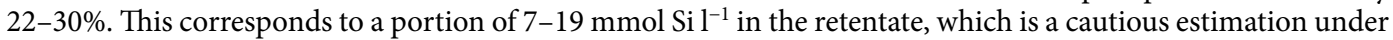
the assumption of no $\mathrm{Al}$ loss. This value is well beyond the solubility of $\mathrm{SiO}_{2(\mathrm{am})}$ at $\mathrm{pH} 7^{37}$. Provided an excess of $\mathrm{Si}$ species was unaffected by the presence of $\mathrm{Al}$, the kinetics of $\mathrm{Si}$ polymerization allow formation of $\mathrm{SiO}_{2(\mathrm{am})}$ within the timeframe of neutralization ${ }^{38}$. Depolymerization rates of $\mathrm{SiO}_{2(\mathrm{am})}$ are also sufficient to consider its dissolution during dialysis ${ }^{39}$. However, incomplete incorporation of Si into SROAS at ambient synthesis conditions but concentrations below $2 \mathrm{mM}$ Si was reported previously and shown to depend on the Al:Si ratio, indicating $\mathrm{Al}$ speciation to be a controlling factor in Si removal ${ }^{40}$. Furthermore, it was shown that Si-rich SROAS are less stable, leading to a structure-dependent preferential mobilisation of $\mathrm{Si}^{41,42}$. Overall, it is thus very likely that $\mathrm{Si}$ was removed from the retentate both by diffusion of Si species that were not incorporated into the solid during neutralization and by the dissolution of unstable Si species during dialysis.

Dry SROAS differed markedly in bulk density, whereas Si-rich SROAS occupied a much greater volume per mass than Al-rich SROAS (Supplementary Fig. S1). Visualized by environmental scanning electron microscopy (ESEM), all variants appeared as micrometre-sized angular particles with visible breaking edges (Supplementary Fig. S2). The SEM images show that Al-rich SROAS (2.6) consisted by trend of larger particles than Si-rich SROAS and aggregate surfaces of Si-rich SROAS appeared rougher (Fig. 1). Both Al-rich SROAS appeared to have smoother aggregate surfaces than Si-rich SROAS (Supplementary Fig. S3). Similar composition-dependent 

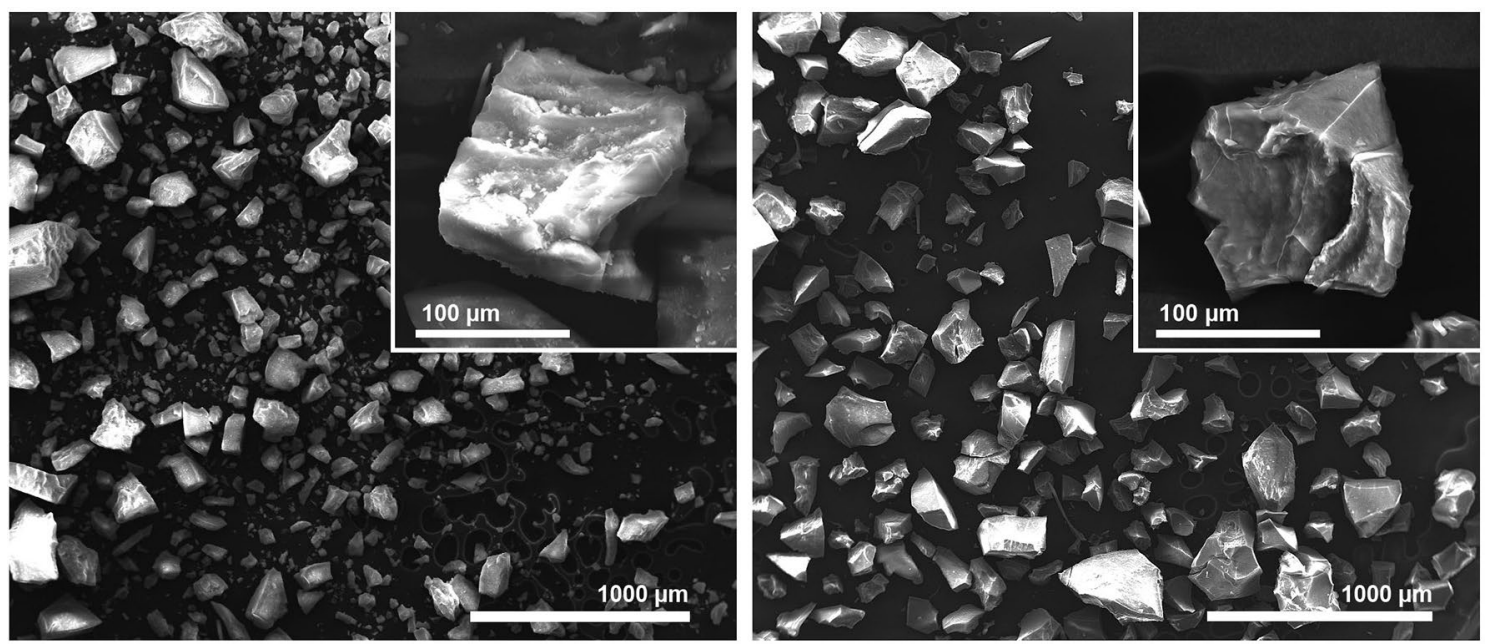

Figure 1. Environmental scanning electron microscopy images of Si-rich (Al:Si 1.4, left) and Al-rich shortrange ordered aluminosilicates (Al:Si 2.6, right). The images were taken by Christian Buchmann.

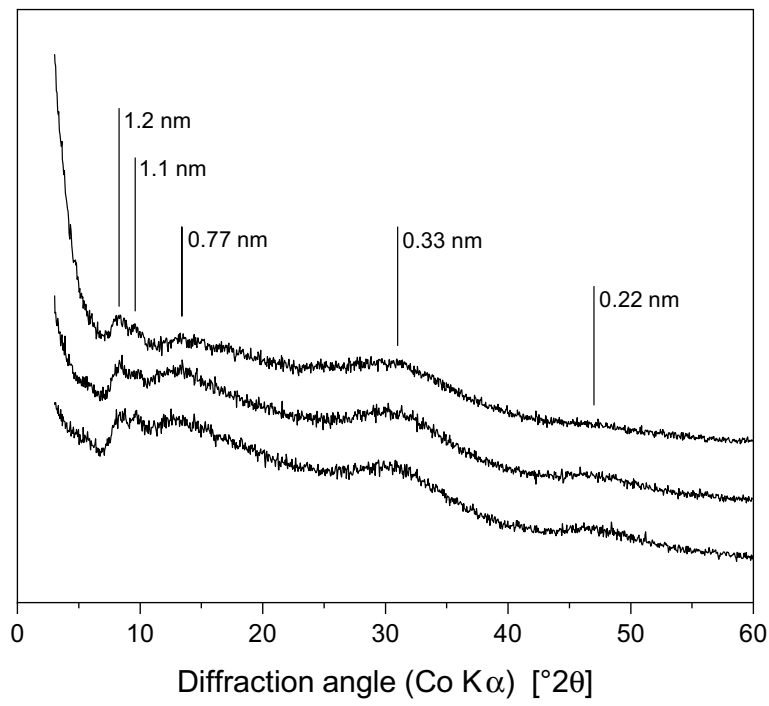

Al:Si 1.4

Al:Si 2.1

Al:Si 2.6

Figure 2. X-ray diffractograms of short-range ordered aluminosilicates. Data is shifted along the y-axis for clarity and given in arbitrary units.

morphological differences were previously described as glassy versus granular aggregates and related to the mineral structure of precipitates ${ }^{43}$.

Mineral structure of SROAS. All materials showed very broad reflections when exposed to Co Ka radiation indicative of a poorly ordered structure (Fig. 2). Reflections centred at $d$-values of $0.77,0.33$ and $0.22 \mathrm{~nm}$ are related to the unit cell of imogolite and were reported in several types of SROAS ${ }^{23,26}$. In Al-rich SROAS, reflections close to 0.77 and $0.22 \mathrm{~nm}$ were slightly more pronounced than in Si-rich SROAS (see Supplementary Fig. S4), pointing to a structural similarity to proto-imogolite of the former. Reflections at $d$-values above $0.9 \mathrm{~nm}$ were previously shown to be related to the extent of assembly of imogolite-like precursors ${ }^{44}$. Hence, poor resolution in this range evidences that structural repetition occurred at very narrow distances in the precipitates only.

All SROAS caused a symmetric peak centred at around $-79 \mathrm{ppm}$ in ${ }^{29} \mathrm{Si}$-NMR spectra indicative of $\mathrm{Si}$ in $\mathrm{Q}^{0}(3 \mathrm{Al})$ coordination $^{24}$ (Fig. 3A). The proportion of Si nuclei in this chemical environment varied from $9 \%$ in Si-rich SROAS to $38 \%$ and $48 \%$ in Al-rich SROAS with Al:Si ratios of 2.1 and 2.6, respectively (Table 1). The presence of $\mathrm{Q}^{0}(3 \mathrm{Al})$ shows that oxolation of $\mathrm{Al}$ and $\mathrm{Si}$ precursors led to locally defined structural domains, but as the kinetics of this process are poorly resolved, it is not clear whether it occurred during the neutralization step or by structural rearrangement during dialysis. Precipitates that formed within one hour by neutralization at ambient conditions at decimolar concentrations analysed previously contained $\mathrm{Si}$ in $\mathrm{Q}^{0}(3 \mathrm{Al})$ coordination together with ill-defined Si environments, indicating that crystallization is initiated rapidly ${ }^{35,44}$. We did not observe any signals at positions above $-79 \mathrm{ppm}^{45}$, demonstrating that small polynuclear species that may have formed during the 


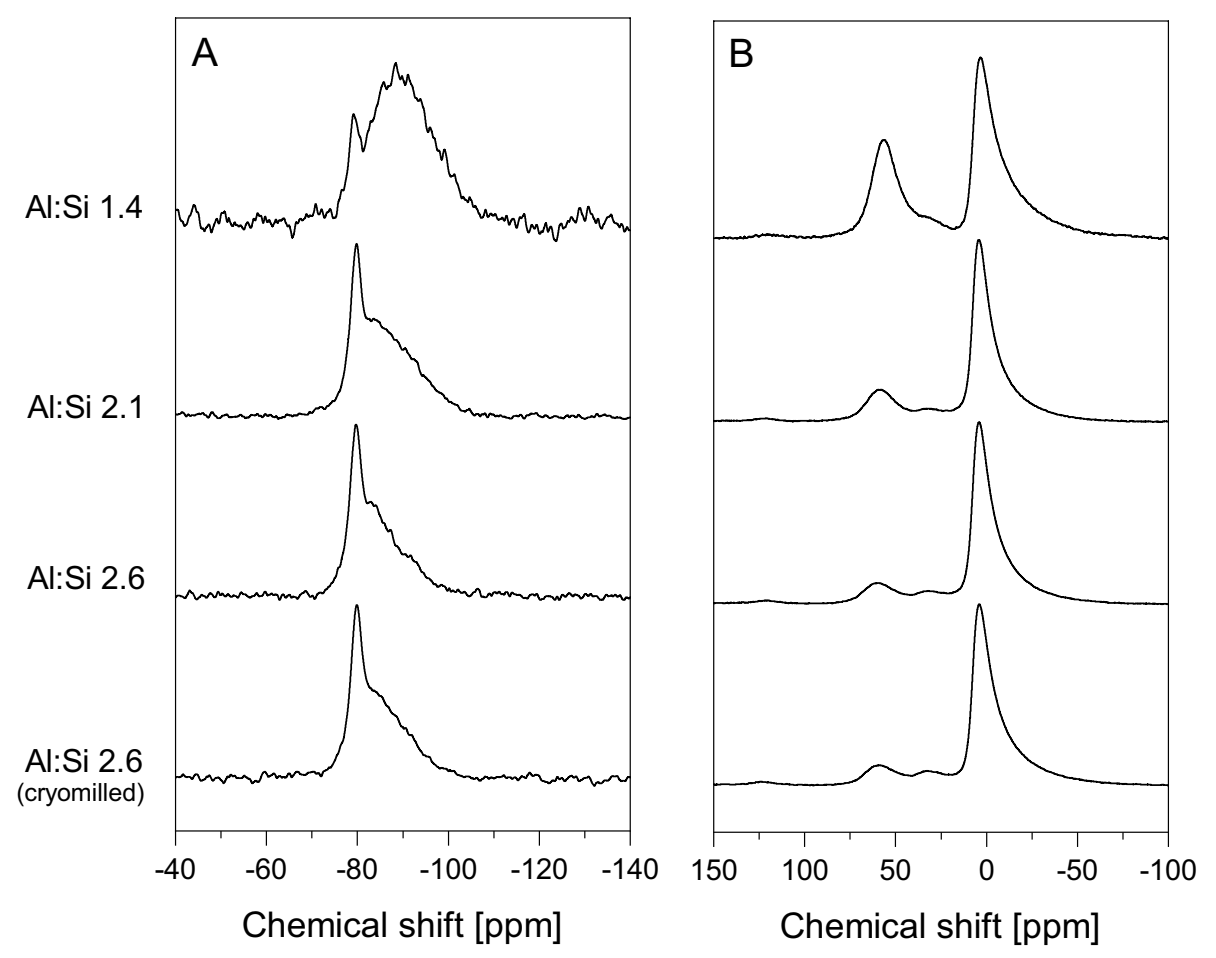

Figure 3. Solid-state nuclear magnetic resonance spectra $\left(\mathbf{A}^{29} \mathrm{Si} ; \mathbf{B}^{27} \mathrm{Al}\right)$ of short-range ordered aluminosilicates at a line broadening of $50 \mathrm{~Hz}$.

initial steps of condensation reactions were consumed prior to structural analysis. At more negative chemical shifts, resonances of ill-defined Si species appeared in the spectra. Condensation of Si tetrahedra causes shielding of Si nuclei and thus upfield chemical shifts, whereas the extent depends on the number of substituted silanol groups ${ }^{46}$. However, the upfield shift is counteracted by reactions with $\mathrm{Al}$, since the deshielding effect of $\mathrm{Al}$ leads to a downfield shift with an increasing number of bonds between $\mathrm{Al}$ and $\mathrm{Si}^{46}$. The intensity distribution between -80 and -110 ppm differed among SROAS, whereas the region at higher chemical shifts was favoured in Alrich SROAS. This indicates that $\mathrm{Si}$ in ill-defined coordination comprised more bonds to $\mathrm{Al}$ nuclei on average in Al-rich SROAS. In Si-rich SROAS, bonds between Si tetrahedra contributed, but the amount of Si nuclei bound to four Si tetrahedra was low as indicated by only small spectral intensities at chemical shifts below $-95 \mathrm{ppm}^{46}$. Consistent with previous reports, we found that the ratio of $\mathrm{Si}$ nuclei in $\mathrm{Q}^{0}(3 \mathrm{Al})$ coordination to nuclei in more ill-defined species decreased with $\mathrm{Si}$ input ${ }^{47}$. The ill-defined fraction was observed to be lost upon heating, indicating its lower stability and transformation in favour of more ordered phases ${ }^{35,44,48}$.

Solid-state ${ }^{27} \mathrm{Al}$ NMR spectra of SROAS exhibited two main peaks attributable to $\mathrm{Al}^{\mathrm{IV}}$ and $\mathrm{Al}$ nuclei in octahedral coordination $\left(\mathrm{Al}^{\mathrm{VI}} \text {; Fig. } 3 \mathrm{~B}\right)^{49}$. The latter was detected by an asymmetric peak exhibiting its maximum at $4 \mathrm{ppm}$ in Al-rich SROAS, the intensity of which constituted $80-85 \%$ of the signal (Table 1). In Si-rich SROAS, this peak was slightly shifted upfield to $3 \mathrm{ppm}$, and its intensity contribution was lower, amounting to $66 \%$. The chemical shift of Al nuclei is not only affected by the number of adjacent oxygen atoms but also sensitive to the structural arrangement of coordination spheres. This can be exploited to conclude the state of the dioctahedral sheet. Octahedral Al in well-crystallized gibbsite resonates at $9.5 \mathrm{ppm}$, which is shifted upfield with structural disorder to $8.5 \mathrm{ppm}$ in X-ray amorphous $\mathrm{Al}$ hydroxides ${ }^{50}$. Octahedral $\mathrm{Al}$ in synthetic imogolite with well-developed tubular morphology exhibits peak maxima at 4-6 $\mathrm{ppm}^{44,48}$. Both synthetic imogolite precursors and natural samples of proto-imogolite obtained from weathered volcanic ejecta contain $\mathrm{Al}^{\mathrm{VI}}$ resonating at $4-6 \mathrm{ppm}^{29,33,51}$. Low chemical shifts of $\mathrm{Al}^{\mathrm{VI}}$ nuclei in $\mathrm{Al}$-rich SROAS thus corroborate results derived from XRD. We conclude that assembly of polynuclear species with a local imogolite-like Si environment did not lead to spatially ordered tube- or ball-shaped particles during synthesis, but rather small, likely curved, fragments $s^{44,48}$.

Both Al- and Si-rich SROAS contained $\mathrm{Al}^{\mathrm{IV}}$ as observed by peaks centred at $56-60 \mathrm{ppm}$. The contribution of $\mathrm{Al}^{\mathrm{IV}}$ increased with Si content from 9 to $13 \%$ in Al-rich SROAS and a further surge to $29 \%$ in Si-rich SROAS (Table 1). Compared with natural samples from altered volcanic ejecta, contents of $\mathrm{Al}^{\mathrm{IV}}$ in Al-rich SROAS were in the same range, but Si-rich SROAS contained more than natural analogues previously characterized (max. $21 \%)^{29}$. A small resonance line at $32-34 \mathrm{ppm}$ indicated traces of $\mathrm{Al}$ in pentahedral coordination $\left(\mathrm{Al}^{\mathrm{V}}\right)^{52}$. Integration of spectra yielded an area contribution of about $5 \%$ for all three SROAS, but quantification is ambiguous due to poor peak separation particularly with Si-rich SROAS ${ }^{52}$. Chemical shifts of $\mathrm{Al}^{\mathrm{IV}}$ in our precipitates resonated in the same range as observed in natural SROAS samples ${ }^{29}$, and its quantity is related to the amount of Si in illdefined species as observed previously in natural and synthetic samples ${ }^{47,51}$. As $\mathrm{Al}^{\mathrm{IV}}$ in tectosilicates and glasses resonates in the same range, this points to its incorporation to a network with Si tetrahedra ${ }^{29}$. Besides, transient 

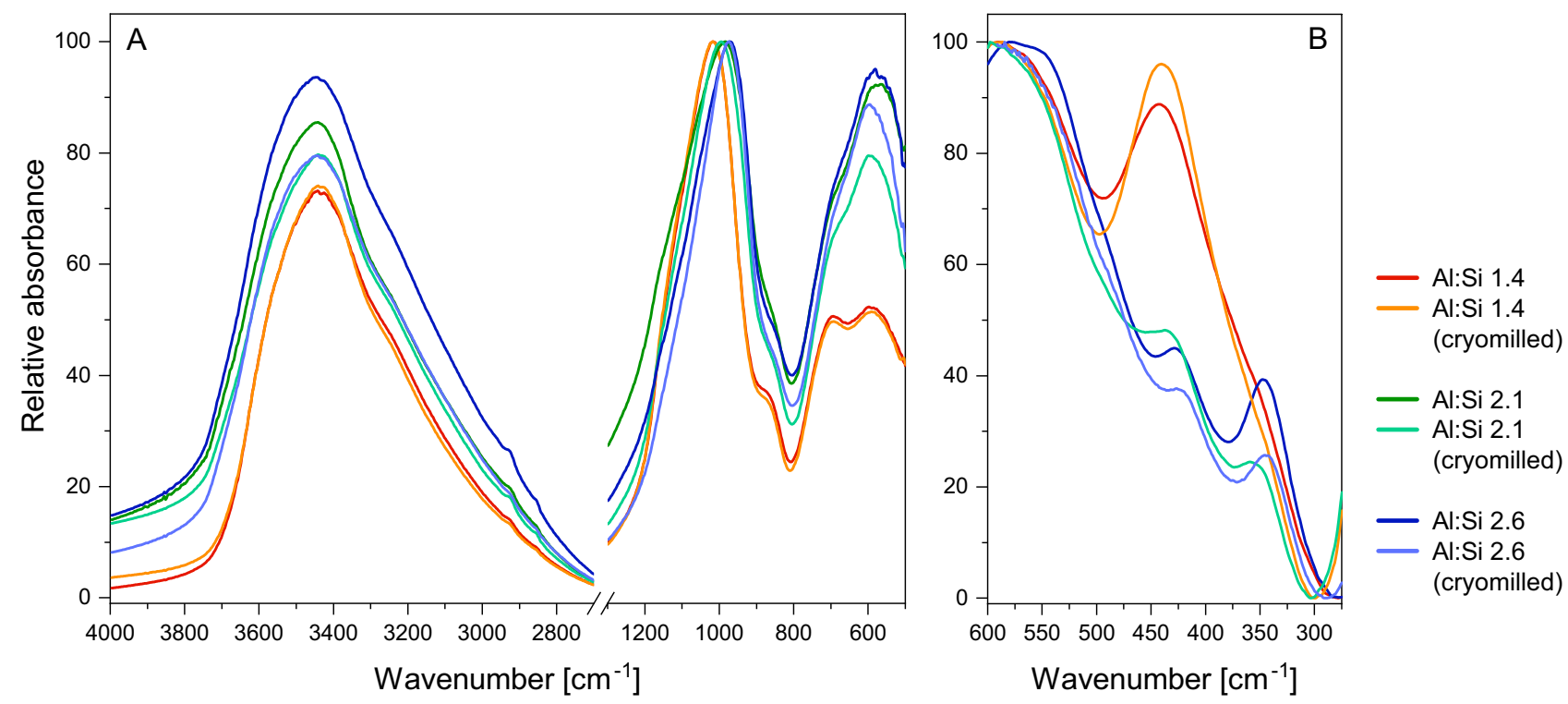

Figure 4. Fourier-transform infrared spectra of short-range ordered aluminosilicates recorded in transmission mode.

species that form during neutralization of $\mathrm{Al}$ salts and contain $\mathrm{Al}^{\mathrm{IV}}$ resonating at $62-65 \mathrm{ppm}$ can be inherited by a small extent into solid poorly ordered Al phases synthesized at ambient conditions ${ }^{50,53,54}$. Such species may also form during synthesis of SROAS and may be located at the edges of fragments of imogolite precursors ${ }^{48}$. The downfield shift with $\mathrm{Al}$ content may thus indicate corresponding structural variations.

Infrared spectra of all SROAS show a broad absorption band centred at $3440 \mathrm{~cm}^{-1}$ due to $\mathrm{OH}$ stretching in hydroxyl groups and at $1640 \mathrm{~cm}^{-1}$ due to $\mathrm{OH}$ bending in adsorbed water (Fig. 4A and Supplementary Fig. S5). There was no difference in shape or position between SROAS. An absorption band between 1018 and $975 \mathrm{~cm}^{-1}$ is caused by stretching vibrations of oxygen bridges formed by condensation of $\mathrm{Si}$ and $\mathrm{Al}^{55}$. This band had the highest intensity for all materials. The position of the band shifted to higher wavenumbers with increasing $\mathrm{Si}$ content due to its sensitivity to the coordination environment of oxygen atoms ${ }^{56,57}$, corroborating the observation by ${ }^{29} \mathrm{Si}$ NMR spectroscopy that the portion of $\mathrm{Al}-\mathrm{O}-\mathrm{Si}$ bonds increased with $\mathrm{Al}$ content relative to the portion of Si-O-Si bonds. All SROAS exhibited an absorption band between 590 and $570 \mathrm{~cm}^{-1}$ due to Al-OH bending vibrations ${ }^{55}$. Relative to the intensity of the band in the $\mathrm{Si}-\mathrm{O}-(\mathrm{Al})$ stretching region, this band decreased in intensity with increasing Si content as observed previously ${ }^{56}$. A shoulder around $870 \mathrm{~cm}^{-1}$ may be related to $\mathrm{Al}-\mathrm{OH}$ bending or $\mathrm{Si}-\mathrm{OH}$ stretching ${ }^{23}$. Characterization of Si-rich SROAS revealed an absorption maximum at $690 \mathrm{~cm}^{-1}$. Regarding Al-rich SROAS, this band only occurred as a shoulder and its intensity was lower relative to Al-OH bending at 590-570 $\mathrm{cm}^{-1}$. This corresponds to a trend previously observed in SROAS with increasing $\mathrm{Si}$ content and is caused by differences in coordination environments of $\mathrm{OH}$ groups related to $\mathrm{Al}$ and $\mathrm{Si}$ speciation $^{56,57}$. In contrast to Al-rich (2.6) SROAS, Si-rich SROAS did not cause a distinct band at $348 \mathrm{~cm}^{-1}$ indicating that the concentration of $\mathrm{Q}^{0}(3 \mathrm{Al})$ was too low to be detected by FTIR (Fig. $\left.4 \mathrm{~B}\right)^{56}$. Both phases showed a band at $430-440 \mathrm{~cm}^{-1}$ related to vibrations of silanol groups, the intensity and frequency of which increased with Si content as observed previously ${ }^{56}$.

Synthesis at high batch volumes and rapid neutralization may favour structural inhomogeneity caused by local $\mathrm{pH}$ gradients ${ }^{45}$, but we did not observe any indication of Al hydroxides or amorphous silica. Crystalline Al hydroxides are detectable by XRD and FTIR, but we did not observe any distinct corresponding feature ${ }^{58}$. However, since poorly crystalline $\mathrm{Al}$ hydroxides may give no reflections in $\mathrm{XRD}^{50,58}$ and reflections in our diffractograms were poorly resolved, we cannot exclude their formation. Aluminium-rich SROAS did not contain polymerized $\mathrm{Si}$ tetrahedra as derived from ${ }^{29} \mathrm{Si} \mathrm{NMR}$ spectra, whereas a pure $\mathrm{SiO}_{2(\mathrm{am})}$ phase is hardly differentiable from aluminosilicate polymers in Si-rich SROAS.

Physical properties as derived from nitrogen sorption. We studied $\mathrm{N}_{2}$ sorption to SROAS to derive SSAs by the BET method and found distinct differences between compositional varieties. Nitrogen sorption increased with Si content and Si-rich SROAS held the greatest SSA of $295.5 \mathrm{~m}^{2} \mathrm{~g}^{-1}$ with a C value of 141 (Table 1 ; Supplementary Table S1). Both parameters decreased in Al-rich (2.1) SROAS to a SSA of $25.6 \mathrm{~m}^{2} \mathrm{~g}^{-1}$ and a C value of 110. Nitrogen sorption to Al-rich (2.6) SROAS was surprisingly low. A specific surface area of $0.7 \mathrm{~m}^{2} \mathrm{~g}^{-1}$ and a $\mathrm{C}$ value $<10$ was derived from linear regression of the BET equation but the magnitude of $\mathrm{N}_{2}$ sorption constrains measurement accuracy ${ }^{59}$. Assuming mineral material to be a monodisperse assemblage of smooth cubic particles, SSA is geometrically related to the edge length by six divided by density $\left[\mathrm{g} \mathrm{cm}^{-3}\right.$ ] times edge length $[\mu \mathrm{m}]^{60}$. Densities of natural and synthetic SROAS with variable Al:Si ratios have been reported to range between 1.8 and $2.7 \mathrm{~g} \mathrm{~cm}^{-361}$. It follows that SSA is driven by the mass fraction of particles with an edge length $<1 \mu \mathrm{m}$. As assessed from particle visualization by ESEM, the mass fraction of particles $<1 \mu \mathrm{m}$ was negligible in both Al-rich (2.6) SROAS and minor in Si-rich (1.4) SROAS. Hence, $\mathrm{N}_{2}$ sorption data of Al-rich (2.6) SROAS 
corresponded well with microscopic characterization and suggested that the solid consisted of dense aggregates that were not penetrated by $\mathrm{N}_{2}$ molecules under measurement conditions. On the other hand, particle sizes of Al-rich (2.1) and particularly Si-rich (1.4) SROAS were not sufficient to explain the higher amount of sorbed $\mathrm{N}_{2}$. This leads to the conclusion that either surface roughness at the submicron scale or intraaggregate porosity advances $\mathrm{N}_{2}$ sorption to these materials.

Synthetic SROAS can exhibit SSA of up to $700 \mathrm{~m}^{2} \mathrm{~g}^{-1}$, but aggregation is a common process restricting surface accessibility of primary particles for $\mathrm{N}_{2}$ molecules and thus frequently resulting in lower values ${ }^{36,44,57}$. However, very low $\mathrm{N}_{2}$ sorption with SSA below $5 \mathrm{~m}^{2} \mathrm{~g}^{-1}$ is rather rare, but has been previously reported ${ }^{44,57,62-64}$. Notably, and in accordance with our results, such a massive surface reduction did only occur in precipitates with an $\mathrm{Al}: \mathrm{Si}$ ratio close to 2 and poor spatial order, indicating that this phenomenon is specific of a certain composition. Precipitates synthesized at ambient temperature by Du et al. ${ }^{44}$ were structurally very similar to our Al-rich (2.6) SROAS and only developed microporous nature and greater SSA upon assembly to tile- and ultimately tubeshaped particles induced by heating. Crystallization was likely inhibited in synthesis protocols that previously reported exceptionally low SSA ${ }^{44,57,62-64}$ either by decimolar concentrations ${ }^{45}$, the presence of counterions during the heating step ${ }^{65}$ or ambient synthesis conditions ${ }^{44}$.

As precipitation by neutralization yielded turbid suspensions of small particles, aggregation resulting in micrometre-sized particles was obviously provoked during the dehydration procedure. Drying conditions varied between synthesis protocols that previously observed very low SSA of Al-rich SROAS ${ }^{44,57,62-64}$ and included freeze-drying ${ }^{44,57,64}$ and drying at $110^{\circ} \mathrm{C}^{63}$ or were not specified ${ }^{62}$. Outgassing of the samples before $\mathrm{N}_{2}$ sorption measurements was done at temperatures from 100 to $400{ }^{\circ} \mathrm{C}$, whereas we worked at $\mathrm{T}=80^{\circ} \mathrm{C}$, since structural changes were reported at $\mathrm{T}>100^{\circ} \mathrm{C}^{66}$. Crystallization of poorly ordered $\mathrm{Al}$ and iron $(\mathrm{Fe})$ phases is accompanied by a substantial loss of SSA and is possible at $\mathrm{T}<100^{\circ} \mathrm{C}^{67,68}$. Although SROAS rearranged structurally upon heating to $\mathrm{T}=100<400^{\circ} \mathrm{C}$, coinciding changes in SSA were small ${ }^{69,70}$, indicating that the magnitude of SSA is imposed on the dry solid beforehand. Indeed, we observed that thawing of frozen synthesis batches yielded clear suspensions with rapidly settling particles and thus assumed that aggregation happened primarily during the freezing process. We repeated $\mathrm{N}_{2}$ sorption analysis of Al-rich (2.6) SROAS obtained by decanting, drying and outgassing at $40{ }^{\circ} \mathrm{C}$. The $\mathrm{N}_{2}$ sorption capacity of decanted aggregates was not substantially larger (calculated $\mathrm{SSA}=1.9 \mathrm{~m}^{2} \mathrm{~g}^{-1}, \mathrm{C}<10$, Supplementary Table $\mathrm{S} 1$ ). We thus conclude that processes during freezing determined the physical properties of the dry mineral material.

Formation of dense aggregates from aqueous suspensions of $\mathrm{Al}$ and $\mathrm{Fe}$ oxides and hydroxides upon freezing was previously observed ${ }^{71}$ and can be explained by physical interactions of ice, liquid water and suspended particles ${ }^{72,73}$. As we froze large volumes $(400 \mathrm{ml})$ of suspension at $-20^{\circ} \mathrm{C}$, cooling was limited by heat conductance of ice and water and ice formation progressed only slowly from the exterior of the volume inward (ca. $\left.0.6-1.4 \mu \mathrm{m} \mathrm{s}^{-1}\right)^{71}$. At such low freezing rates, particles with a diameter $<1 \mu \mathrm{m}$ are expelled from the freezing front and transported ${ }^{72}$. This phenomenon is caused by repulsive forces caused by surface tension of a film of liquid water between the freezing front and the particle ${ }^{72}$. The co-occurrence of ice and liquid water induces migration of the latter to the former, usually referred to as cryosuction. When suspensions with sufficient particle concentration are slowly frozen, the combination of particle repulsion and cryosuction leads to a concentrated layer of particles ahead of the freezing front ${ }^{73,74}$. As this layer freezes, colloidal suspensions are segregated on a macroscopic scale into areas with crack-like boundaries between ice and particle enriched zones ${ }^{73,74}$. Similar segregation phenomena are likely responsible for the shape of SROAS aggregates we observed by ESEM as sublimation of ice led to the disintegration of frozen batches. Stress caused by cryosuction and freezing has been observed to be sufficient to overcome electrostatic repulsion between particles and cause particle packing into clusters that do not disintegrate after thawing ${ }^{71,74,75}$. Interfacial effects reducing the mobility of water molecules and inhibiting complete crystallization ${ }^{76}$ ultimately limit the dehydration of poorly crystalline solids. Consistently, porosity analysis of Fe (hydr)oxide aggregates indicated that crystallites were separated by a hydration layer ${ }^{71}$. The magnitude of SSA of Al-rich SROAS and the fact that it is not substantially affected by outgassing evidence that inaccessibility of interparticle spaces to $\mathrm{N}_{2}$ molecules was caused by freezing and homogeneously distributed within the material since otherwise water emission would have created porosity. Small pore sizes and possibly sorbed water likely restricted $\mathrm{N}_{2}$ diffusion, an effect that is particularly relevant for pores $<1 \mathrm{~nm}^{77}$. Taking this effect into account by assuming a maximal pore radius of $2 \mathrm{~nm}$, calculation of the respective particle diameter that is necessary to explain impermeable aggregate surfaces on the basis of cubic close-packing of monodisperse spheres gives a value of $4.8 \mathrm{~nm}$ (see Supplementary information). Considering the hydration layer $(0.9-2 \mathrm{~nm})^{71}$, this calculation illustrates that primary building entities have to be $<4 \mathrm{~nm}$ as structural analysis already indicated. Consistent with previous reports, we observed an increase in SSA with Si content in poorly ordered SROAS ${ }^{57,63,78}$, pointing to a structure-dependent effect on the spatial arrangement of mass at the submicron scale. In summary, increasing incorporation of Si into poorly ordered SROAS or advanced crystallization of Al-rich SROAS seems to cause resistance to compaction and consequently a rise in SSA.

Considering mechanisms and forces responsible for SROAS aggregation, Wells and Childs ${ }^{79}$ proposed a model based on the assembly of hollow spheres that recognized the degree of water removal as a measure to quantify the interactions between particles. As long as the hydration layer prevails around particles, van der Waals forces and electrostatic interactions are perceived to be responsible for holding particles together ${ }^{79}$, with a possible contribution of aluminol-group condensation ${ }^{80}$. The latter is especially likely during the formation of Al-rich SROAS in our syntheses by concentration of small Al-rich fragments. Our results show that incorporation of $\mathrm{Si}$ interferes with aggregation, but the mechanisms are not clear yet. Both the presence of silanol groups and oxygen bridges between Si tetrahedra as well as the formation of $\mathrm{Al}^{\mathrm{IV}}$ imposes changes on surface properties that may lead to variations in interfacial processes between particles and water dynamics. 


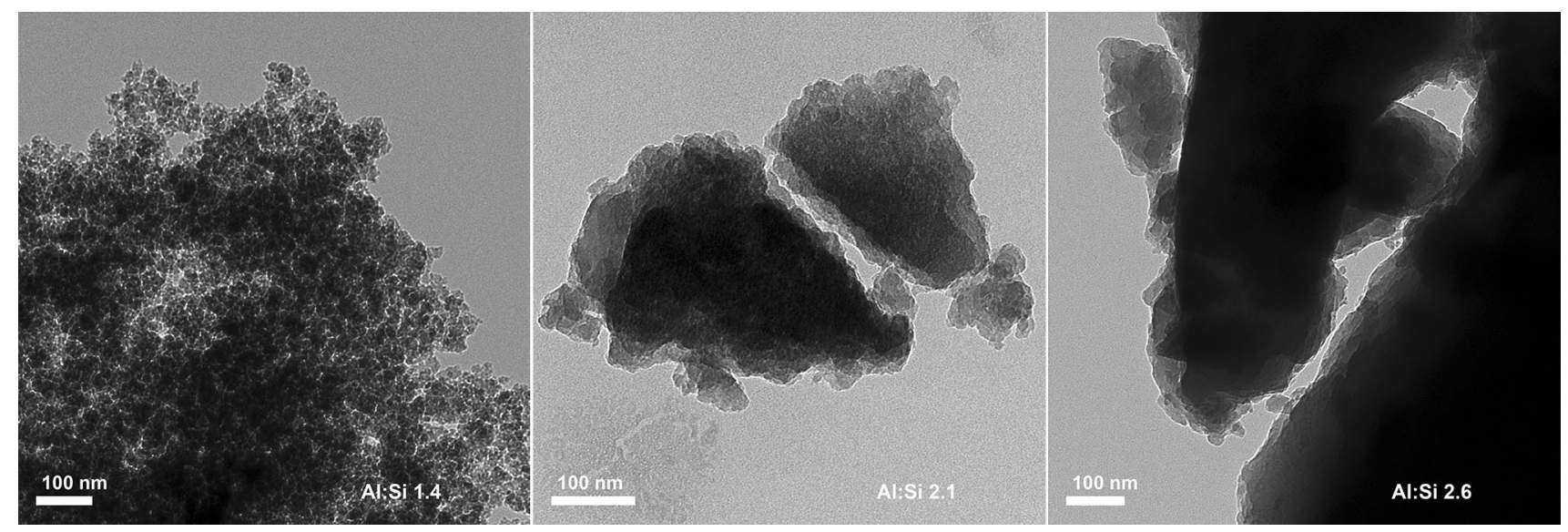

Figure 5. Transmission electron microscopy images of cryomilled Si-rich (Al:Si 1.4, left) and Al-rich (Al:Si 2.1 and 2.6, middle and right, respectively) short-range ordered aluminosilicates.
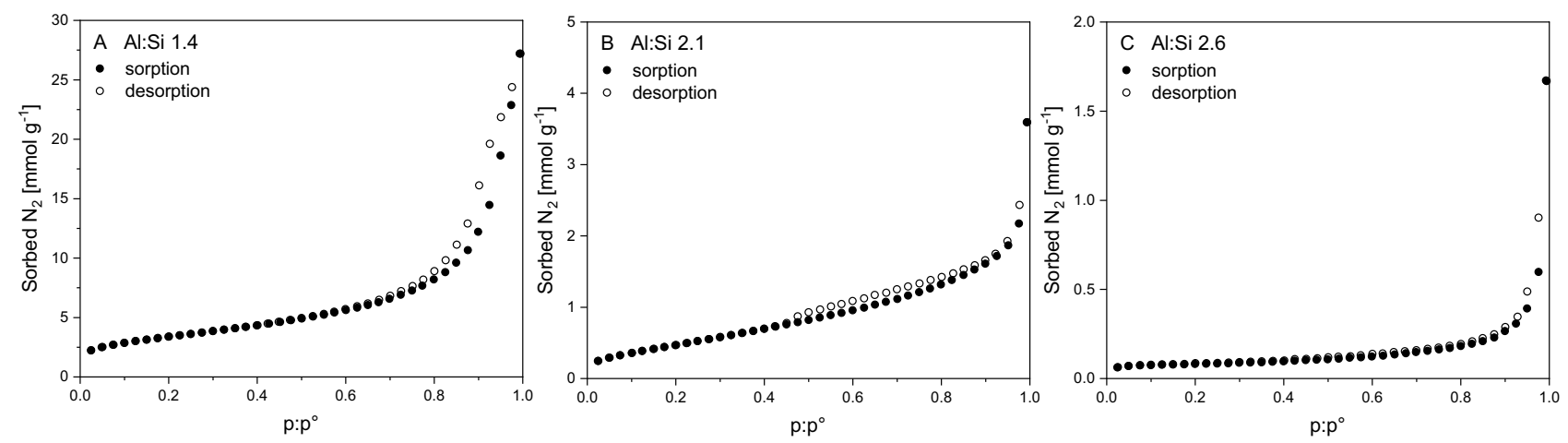

Figure 6. Nitrogen sorption and desorption isotherms at $-196^{\circ} \mathrm{C}$ of cryomilled short-range ordered aluminosilicates with varying Al:Si ratios (A 1.4; $\mathbf{B} 2.1$; C 2.6).

Effects of cryomilling on particle size, mineral structure and SSA. We aimed at increasing the yield of particles with diameters $<1 \mu \mathrm{m}$ and greater SSA of mineral material and thus decided to mill SROAS. It was previously shown that SROAS are sensitive to heating and mechanical stress, resulting in structural changes ${ }^{66,81}$. Hence, we employed mechanical treatment of dry material under constant cooling with liquid $\mathrm{N}_{2}$, i.e. cryomilling. Cryomilling of metallic powders was shown to accelerate fracturing of particles but suppress structural rearrangement ${ }^{82}$. We investigated particle size and morphology in resulting powders by transmission electron microscopy (TEM). We did not find particles with diameters $>15 \mu \mathrm{m}$, indicating that cryomilling efficiently crushed aggregates already after 2-5 min (Supplementary Fig. S6). We found striking differences in particle morphology between Si-rich and Al-rich SROAS (Fig. 5). Both Al-rich SROAS assembled into aggregates of variably sized, dense particles with defined boundaries. On the contrary, Si-rich SROAS appeared as finely differentiated clusters, which could be observed as loose aggregates on the TEM carbon grid but rarely as particles with defined barriers. Many Al-rich SROAS particles with a diameter $>300 \mathrm{~nm}$ had an angular shape probably retained from disruption of primary material (Supplementary Fig. S7).

Inspection for structural rearrangement by FTIR spectroscopy of cryomilled samples revealed only small changes. Neither spectra showed a shift in the position of stretching vibrations of Si-O-Al bridges (1018-975 $\mathrm{cm}^{-1}$ ), but spectra of both Al-rich SROAS exhibited a small relative decrease of absorption by $\mathrm{Al}-\mathrm{OH}$ bending at $595 \mathrm{~cm}^{-1}$ (Fig. 4A). At lower wavenumbers, absorption at $348 \mathrm{~cm}^{-1}$ in Al-rich SROAS (2.6) decreased, while absorption at $440 \mathrm{~cm}^{-1}$ in Si-rich SROAS increased (Fig. 4B). Hence, the spectra point to small changes of $\mathrm{Si}$ speciation induced by cryomilling, which led to a particular interest in the behaviour of $\mathrm{Si}$ in $\mathrm{Q}^{0}(3 \mathrm{Al})$ coordination. We thus repeated solid-state NMR spectroscopic analyses of Al-rich (2.6) SROAS, showing that $\mathrm{Si}$ in $\mathrm{Q}^{0}(3 \mathrm{Al})$ coordination was largely retained after cryomilling, but small amounts of more ill-defined species were generated by mechanical treatment in spite of low temperatures (Fig. 3A, Table 1). We did not try to resolve such changes in Si-rich SROAS, since ${ }^{29}$ Si NMR spectroscopy yielded a poor resolution of Si speciation in the primary material.

In addition to particle visualization by TEM, we employed $\mathrm{N}_{2}$ sorption experiments over the whole range of relative pressure to derive SSA and porosity of cryomilled SROAS. Silicon-rich (1.4) SROAS remained to be the strongest $\mathrm{N}_{2}$ sorbent after cryomilling. The measured sorption capacity at relative pressures below 0.35 was slightly lower compared to unmilled solid, resulting in a decrease of SSA by $7.2 \%$ (Table 1), but effects of this size might be related to measurement inaccuracy. We observed desorption hysteresis at relative pressures above 
0.7 (Fig. 6A), indicating the presence of mesopores with diameters from 2 to $50 \mathrm{~nm}^{83}$. Evaluation of $\mathrm{N}_{2}$ sorption data with respect to micropore volume suggested negligible contribution of pores in this size range $(<2 \mathrm{~nm})^{59}$. Nitrogen sorption to Al-rich SROAS increased after cryomilling, causing enhanced SSA $\left(43.2\right.$ and $6.9 \mathrm{~m}^{2} \mathrm{~g}^{-1}$ for solids with Al:Si ratios of 2.1 and 2.6, respectively; Table 1). None of the sorption branches exhibited a distinct knee indicating completion of the monolayer and there was thus no evidence of accessible micropores (Fig. 6B,C). For Al-rich (2.1) SROAS, we detected desorption hysteresis between relative pressures of 0.45 and 0.9 evidencing present mesopores to have smaller diameters on average than in Si-rich SROAS. As assessed from the shape of $\mathrm{N}_{2}$ sorption isotherms (Fig. 6C), Al-rich (2.6) SROAS appeared as a non-porous solid ${ }^{59}$. Nitrogen sorption experiments accorded with TEM observations and confirmed spatial matter segregation in Si-rich SROAS at scales $<100 \mathrm{~nm}$, offering porosity and considerable SSA. On the other hand, Al-rich SROAS consisted of consolidated particles. Our results demonstrate that nanoscale compaction of synthetic SROAS cannot be reversed by cryomilling as it does not change the magnitude of SSA, limiting the feasibility of a top-down approach to mineral synthesis. Furthermore, structural changes already occurring at short milling durations suggest that prolonged milling is not an option.

Implications of structure-related aggregation effects for the reactivity of SROAS in the environment. A comparison of spectroscopic properties of synthesized SROAS with natural analogues supports structural similarity. As assessed from Si speciation and elemental analysis, Al-rich SROAS resembled protoimogolite phases precipitated from waters percolating shales and volcanic rocks (designated as Derbyshire allophane and $\mathrm{Ki}-\mathrm{P})^{51,84}$. Furthermore, FTIR spectra indicated a similar composition to Al-rich (Al:Si $\left.>2.8\right)$ samples isolated from Podzols ${ }^{10}$. An Si-rich SROAS separated from andesitic ashes exhibited structural similarity to our synthetic Si-rich SROAS with respect to Al:Si ratio, Si speciation and content of $\mathrm{Al}^{\mathrm{IV}}$ (designated as Okamoto allophane ${ }^{29,51}$. Specific surface areas of natural SROAS determined by $\mathrm{N}_{2}$ sorption ranged from 21 to $478 \mathrm{~m}^{2} \mathrm{~g}^{-170,85-87}$, whereas isotherms indicated the presence of micropores ${ }^{87}$. Values of SSA of naturally precipitated SROAS are thus in the same range as observed for synthetic samples, but as Al:Si ratio and structural properties were scarcely characterized, the relation of composition to SSA in natural samples remains ambiguous.

However, irreversible aggregation is a well-known phenomenon in both bulk soil containing SROAS and particle-size fractions. Andic soil material was irreversibly compacted upon water removal ${ }^{88}$ and lost substantial SSA compared to a treatment without capillary stress ${ }^{89,90}$. Freeze-drying of clay fractions from an andic subsoil caused the formation of micrometre-sized aggregates $(>20 \mu \mathrm{m})^{91}$ and aggregation of clay-sized particles was also observed to be caused by air-drying ${ }^{92}$. Saturation deficits at ambient temperature and relative humidity are sufficient to induce a decrease in water retention capacity ${ }^{93}$ and sorption capacity of ionic species to SROAS ${ }^{80,94}$, evidencing physical reorganization to affect the accessible surface. Both evaporation of water and physical processes occurring during freezing lead to a spatial concentration of mineral mass, which causes particles to interact. The dehydration efficacy likely depends on the drying method, whereas it may be higher in freezing compared to air-drying at ambient temperatures.

In soils and sediments, the water regime determines the degree of SROAS dehydration. Formation of SROAS requires sufficient silicate weathering that intensifies under a udic moisture regime. However, SROAS aggregation is enhanced by drying so that aggregation is likely most pronounced in soil with fluctuating water contents. Such conditions prevail for example in sandy substrates, where drying can progress into the subsoil. Precipitation of Al-rich SROAS led to induration of subsoil horizons by the formation of continuous coatings of SROAS with Al:Si ratio of about 2 in andesitic deposits ${ }^{95}$ and podzolic soils ${ }^{96,97}$. Characterization by FTIR spectroscopy evidenced a coating with $\mathrm{Si}$ in $\mathrm{Q}^{0}(3 \mathrm{Al})$ conformation ${ }^{96}$. Based on our results, we expect such strongly dehydrated $\mathrm{Al}$-rich precipitates to be relatively unreactive, as aggregation likely decreased accessibility of surface functional groups. Association of SROAS with SOM interferes with physical processes of aggregation and particles assembled less efficiently in topsoils upon drying ${ }^{92}$. SROAS separated from a soil horizon that was characterized by SOM accumulation was structurally different from our precipitates regarding $\mathrm{Al}$ speciation, evidencing molecular interactions between SOM and SROAS that affected structure and potentially masked aluminol groups ${ }^{33}$. Besides structure, the water regime and presence of SOM should thus be included in studies on physicochemical mechanisms of SROAS aggregation.

\section{Conclusion}

We synthesized SROAS with variable Al:Si ratios that exhibit structural features similar to poorly crystalline phases precipitating in soils and weathered volcanic ejecta. As we employed ambient conditions, precipitates did not develop a ball- or tube-like morphology and thus likely had a functional group distribution similar to natural nanoscale initial weathering products. We propose that aqueous suspensions contained small polynuclear species that resembled precursors of Al- and Si-rich imogolite and allophane. Our results indicate that composition and crystallinity severely alter the accessibility of functional groups due to changes in aggregation mechanisms during dehydration. Incorporation of Si led to an increase in specific surface area, potentially evidencing a physicochemical impact on SROAS reactivity. Studying physical processes causing aggregation of poorly crystalline minerals as a function of structural properties may thus improve our understanding of their adsorption behaviour in the natural environment. Retention of organic substances by SROAS is particularly relevant for carbon sequestration in soils and sorption of nutrients, i.e. phosphate, which affects their bioavailability. With respect to future syntheses, we recommend careful customization of dehydration conditions. 


\section{Materials and methods}

Precipitation of SROAS. We synthesized SROAS of variable Al:Si ratios at ambient temperature and pressure by neutralizing a $0.2 \mathrm{M}$ aluminium chloride hexahydrate solution ( $\mathrm{AlCl}_{3}$; AppliChem $\mathrm{GmbH}$, Darmstadt, Germany) with sodium orthosilicate $\left(\mathrm{Na}_{4} \mathrm{SiO}_{4}\right.$; abcr $\mathrm{GmbH}$, Karlsruhe, Germany). Due to the $\mathrm{pH}$ conditions of the stock solutions, both reactants were in monomeric form, i.e. Al in hexacoordinated, partially hydrolysed, aquacomplexes $(\mathrm{pH}<3)^{53}$ and $\mathrm{Si}$ as monomeric silicic acid and dissociated silicate ions ${ }^{98}$. After mixing the stock solutions, the batch volume contained $67 \mathrm{mmol} \mathrm{Al}$ and 33, 44 or $67 \mathrm{mmol} \mathrm{Si}$, resulting in molar Al:Si ratios of 1, 1.5 and 2, respectively. Synthesis procedures differed between variants with respect to the course of neutralization. Each synthesis procedure was carried out in triplicate. Titration data is presented in Supplementary Fig. S8. A Si-rich SROAS (Al:Si = 1) was precipitated by mixing 11 of a $0.2 \mathrm{M} \mathrm{AlCl}_{3}$ solution with 21 of a $0.1 \mathrm{M} \mathrm{Na}_{4} \mathrm{SiO}_{4}$ solution under vigorous stirring within approximately $1 \mathrm{~min}$. The $\mathrm{AlCl}_{3}$ solution was acidified with $70 \mathrm{ml}$ of a $1 \mathrm{M} \mathrm{HCl}$ solution (Chemsolute, Th. Geyer GmbH \& Co. KG, Renningen, Germany) beforehand to keep synthesis $\mathrm{pH}<7$. The final suspension had a $\mathrm{pH}$ of $6.6( \pm 0.3$; glass electrode, InLab Expert Pro, Mettler Toledo, Gießen, Germany) and was stirred for $1 \mathrm{~h}$, during which the $\mathrm{pH}$ increased slightly (+0.2). An Al-rich SROAS (Al:Si $=2)$ was synthesized by mixing 11 of a $0.2 \mathrm{M} \mathrm{AlCl}_{3}$ solution with 11 deionized $\mathrm{H}_{2} \mathrm{O}$ and 11 of a $0.1 \mathrm{M} \mathrm{Na}_{4} \mathrm{SiO}_{4}$ solution. The resulting suspension had a pH of $3.8( \pm 0.04)$ and was further neutralized with $234( \pm 2) \mathrm{ml}$ of $1 \mathrm{M}$ $\mathrm{NaOH}\left(1.17 \mathrm{~mol} \mathrm{OH}^{-} \mathrm{mol}^{-1} \mathrm{Al}^{-1}\right.$, AppliChem $\left.\mathrm{GmbH}\right)$ within $30 \mathrm{~min}$. Final pH was $6.1( \pm 0.1)$ and stable during a further 30 min of stirring. Another SROAS (Al:Si=1.5) was precipitated by mixing $1 \mathrm{l}$ of a $0.2 \mathrm{M} \mathrm{AlCl}_{3}$ solution with $2 \mathrm{l}$ of a $0.067 \mathrm{M} \mathrm{Na}_{4} \mathrm{SiO}_{4}$ solution, resulting in a suspension with $\mathrm{pH} 4( \pm<0.1)$ that was neutralized (pH $6.4 \pm 0.2)$ with $131( \pm 2) \mathrm{ml} 1 \mathrm{M} \mathrm{NaOH}\left(0.66 \mathrm{~mol} \mathrm{OH}^{-} \mathrm{mol}^{-1} \mathrm{Al}^{-1}\right)$. The $\mathrm{pH}$ was constant during another $30 \mathrm{~min}$ of stirring. Suspensions were subsequently transferred to dialysis membranes with a molecular weight cut-off of $14 \mathrm{kDa}$ (Viskase $\mathrm{GmbH}$, Köln, Germany) and dialysed for one week until the electrical conductivity in the permeate was below $5 \mu \mathrm{S} \mathrm{cm}{ }^{-1}$ for $24 \mathrm{~h}$.

Retrieval and cryomilling of the solids. As separation by centrifugation and filtration was not practicable, we decided to achieve mass retrieval by freeze-drying. After dialysis, about $400 \mathrm{ml}$ of suspension volume were filled into polyethylene bottles and frozen at $-20^{\circ} \mathrm{C}$ in a conventional freezer. Shortly after complete freezing, the suspensions were freeze-dried and pooled per Al:Si variant. Three bottles of frozen Al-rich SROAS suspensions (initial Al:Si ratio = 2) were excluded from this procedure and thawed at room temperature. Rapidly settling precipitates were decanted, pooled and dried at $40^{\circ} \mathrm{C}$. A portion of each variant of freeze-dried material was ground with a ball mill under constant cooling with liquid $\mathrm{N}_{2}$ (CryoMill, Retsch, Haan, Germany). About $3 \mathrm{~g}$ were filled into the sample chamber, which was then precooled for $3 \mathrm{~min}$ and subsequently shaken at a frequency of $30 \mathrm{~Hz}$. Samples did not come into contact with liquid $\mathrm{N}_{2}$. We chose a shaking time of $2 \mathrm{~min}$ for Si-rich SROAS and $5 \mathrm{~min}$ for both Al-rich SROAS.

Characterization of unground SROAS. Morphology of the synthesized SROAS was studied by ESEM under low vacuum and acceleration voltage of $30 \mathrm{kV}$ (FEI Quanta 250 ESEM, FEI Company, Hillsboro, United States). Their elemental composition was determined by microwave digestion of $0.1 \mathrm{~g}$ in $28 \mathrm{ml}$ deionised water, $2.5 \mathrm{ml} 68 \% \mathrm{HNO}_{3}$ and $0.5 \mathrm{ml} \mathrm{40 \%} \mathrm{HF.} \mathrm{Aluminium,} \mathrm{Si}$ and $\mathrm{Na}$ concentrations were quantified by inductively coupled plasma optical emission spectrometry (ICP-OES; Agilent 5110, Agilent Technologies, Waldbronn, Germany). Mineral structure was investigated by XRD, FTIR, ${ }^{27} \mathrm{Al}$ and ${ }^{29} \mathrm{Si}$ NMR spectroscopy. Mineral powders prepared by grinding in a mortar were exposed to Co Ka radiation $(\lambda=0.179 \mathrm{~nm})$, and diffraction patterns were recorded from 3 to $60^{\circ} 2 \theta$ at a step size of $0.05^{\circ} 2 \theta$ and a counting time of $1.5 \mathrm{~s}$ (D500, Siemens, München, Germany). We obtained FTIR spectra at wavenumbers from 4000 to $500 \mathrm{~cm}^{-1}$ with the transmission accessory of a LUMOS infrared microscope (Bruker, Ettlingen, Germany). Pellets were prepared from mixtures of $1 \mathrm{mg}$ of ground sample and 200-280 mg of KBr. Fifty background spectra were recorded against the atmosphere, and subsequently 100 sample scans accumulated at a resolution of $4 \mathrm{~cm}^{-1}$. Spectra at wavenumbers from 600 to $270 \mathrm{~cm}^{-1}$ were measured with a Nicolet 5700 spectrometer accumulating 64 scans at a resolution of $2 \mathrm{~cm}^{-1}$ (Thermo Scientific, Darmstadt, Germany). Pellets were prepared at the same mass ratio, but with a hydraulic press. The chemical environment of ${ }^{27} \mathrm{Al}$ and ${ }^{29} \mathrm{Si}$ nuclei was studied by solid-state NMR spectroscopy with direct-polarization (DP) and magic angle spinning (MAS) on a $400 \mathrm{MHz}$ Bruker Avance II + spectrometer, equipped with a $4 \mathrm{~mm} \mathrm{H} / \mathrm{X}$ MAS probe. Samples were spun in $4 \mathrm{~mm}$ zirconia rotors. ${ }^{27} \mathrm{Al}$ NMR spectra were obtained at a resonance frequency of $104.3 \mathrm{MHz}$ and a MAS frequency of $12 \mathrm{kHz}$. A DP pulse of $22^{\circ}$ was applied and relaxation delay was set to $4 \mathrm{~s} .{ }^{1} \mathrm{H}$ was decoupled with a tppm 20 pulse sequence. Between 64 and 256 scans were accumulated. Chemical shifts are expressed relative to an aqueous solution of $\mathrm{AlCl}_{3} \cdot{ }^{29} \mathrm{Si} \mathrm{NMR}$ spectra were recorded at a resonance frequency of $79.5 \mathrm{MHz}$ and a MAS frequency of $8 \mathrm{kHz}$. Decoupling of ${ }^{1} \mathrm{H}$ was achieved with a spinal 64 pulse sequence. A number of $2127-3072$ scans were acquired with DP by a $22^{\circ}$ pulse $(2 \mu$ s) and a delay time of $120 \mathrm{~s} .{ }^{29} \mathrm{Si}$ spectra were referenced to tetramethylsilane. All data was collected at an acquisition time of $0.04096 \mathrm{~s}, 4096$ observation points and a spectral width of $50 \mathrm{kHz}$, giving a resolution of $12.02 \mathrm{~Hz}$. Phase adjustment and baseline correction was conducted with TopSpin 4.0.7 (Bruker). The quantitative contribution of Si nuclei in $\mathrm{Q}^{0}(3 \mathrm{Al})$ coordination was derived from fitting Lorentzian functions to spectral data and calculating the proportion of integrals to the total area of the resonance signal (OriginPro 2020, OriginLab Corporation, Northhampton, USA). Spectra were normalized and base line was set to the median of all data points. The position of the resonance signal of ${ }^{29} \mathrm{Si}$ in $\mathrm{Q}^{0}(3 \mathrm{Al})$ coordination was fixed to the maximum of the visible peak at $-79 \mathrm{ppm}$, whereas no specifications were made for other nuclei. Resonance of these ill-defined species was reproduced by 3-5 functions with no specification of peak position, height or width (see Supplementary Fig. S9). We first analysed the data at a line broadening $>0 \mathrm{~Hz}$ to identify positions of local maxima and then repeated the fit with spectra at a line broadening of $0 \mathrm{~Hz}$ to obtain integrals. We modelled ${ }^{27} \mathrm{Al} \mathrm{NMR}$ spectra at a line broaden- 
ing of $0 \mathrm{~Hz}$ with a combination of Gaussian and Lorentzian functions, whereas neither peak position nor width or height was fixed (see Supplementary Fig. S10). Integrals of functions were ascribed to a coordination of $\mathrm{Al}$ according to the chemical shift ${ }^{49}$ and summed.

We determined the SSA by $\mathrm{N}_{2}$ sorption to freeze-dried, unground SROAS manometrically at eleven points below a relative pressure of 0.35 with an Autosorb AS 1 at $-196^{\circ} \mathrm{C}$ (Quantachrome Instruments, Boynton Beach, USA) after degassing the samples at $80^{\circ} \mathrm{C}$ until the pressure increase was $<0.067 \mathrm{mbar} \mathrm{min}^{-1}$. Volume was recorded after 5 min of equilibration. Measurements were replicated three times. A sample of Al-rich SROAS obtained by decanting was analysed at 10 points after 2 min equilibration time on a Quantachrome Autosorb iQ (Anton Paar Quanta Tec Inc., USA) after degassing at $40{ }^{\circ} \mathrm{C}$ for $24 \mathrm{~h}^{67}$. Specific surface area was derived by linear regression with the Brunauer-Emmett-Teller (BET) equation after selecting data points in the range of continuous increase in sorbed $\mathrm{N}_{2}$ times $\left(\mathrm{p}^{\circ}-\mathrm{p}\right)$ with $\mathrm{p}: \mathrm{p}^{\mathrm{o59}}$.

Characterization of cryomilled SROAS. Structural analysis by FTIR and NMR spectroscopy was conducted as described above. Specific surface area and porosity were analysed by determining both $\mathrm{N}_{2}$ sorption and desorption isotherms on a Quantachrome Autosorb iQ after degassing at $60{ }^{\circ} \mathrm{C}$ for at least $8 \mathrm{~h}$. Specific surface area was calculated as described above. Total pore volume $\left(\mathrm{V}_{\mathrm{T}}\right)$ was obtained from the volume of sorbed $\mathrm{N}_{2}$ at $\mathrm{p}: \mathrm{p}^{\circ}=0.99$. Respective volumes of pores with a diameter in the mesopore range $(2-10 \mathrm{~nm}, 10-50 \mathrm{~nm})$ were derived from the desorption branch according to the Barret-Joyner-Halenda $(\mathrm{BJH})$ method $^{83}$. To visualize particles by TEM, a small portion of mineral material was dispersed in $98 \%$ ethanol, deposited on carbon grids and dried protected overnight at room temperature to remove the excess liquid before insertion in the UHV imaging chamber. Images were recorded with a FEI Tecnai G2 (FEI Europe B.V., Biedermannsdorf, Austria) with $160 \mathrm{kV}$ acceleration voltage.

\section{Data availability}

The datasets generated during the current study are available from the corresponding author on reasonable request.

Received: 16 December 2020; Accepted: 4 February 2021

Published online: 18 February 2021

\section{References}

1. Gérard, M., Caquineau, S., Pinheiro, J. \& Stoops, G. Weathering and allophane neoformation in soils developed on volcanic ash in the Azores. Eur. J. Soil Sci. 58, 496-515 (2007).

2. Jongmans, A. G., Verburg, P., Nieuwenhuyse, A. \& van Oort, F. Allophane, imogolite, and gibbsite in coatings in a Costa Rican Andisol. Geoderma 64, 327-342 (1995).

3. Basile-Doelsch, I. et al. Mineralogical control of organic carbon dynamics in a volcanic ash soil on La Réunion. Eur. J. Soil Sci. 56, 689-703 (2005).

4. Hiradate, S., Hirai, H. \& Hashimoto, H. Characterization of allophanic Andisols by solid-state ${ }^{13} \mathrm{C},{ }^{27} \mathrm{Al}$, and ${ }^{29} \mathrm{Si} \mathrm{NMR}$ and by C stable isotopic ratio, $\delta^{13}$ C. Geoderma 136, 696-707 (2006).

5. Rennert, T. et al. Characterisation of Andosols from Laacher See tephra by wet-chemical and spectroscopic techniques (FTIR, $\left.{ }^{27} \mathrm{Al}-,{ }^{29} \mathrm{Si}-\mathrm{NMR}\right)$. Chem. Geol. 363, 13-21 (2014).

6. Henmi, T. The occurrence of allophane in a stream-deposit from Ehime-prefecture, Japan. Clay Miner. 14, 333-338 (1979).

7. Wells, N., Childs, C. W. \& Downes, C. J. Silica Springs, Tongariro National Park, New Zealand-Analyses of the spring water and characterisation of the alumino-silicate deposit. Geochim. Cosmochim. Acta 41, 1497-1506 (1977).

8. Gustafsson, J. P., Bhattacharya, P. \& Karltun, E. Mineralogy of poorly crystalline aluminium phases in the B horizon of Podzols in southern Sweden. Appl. Geochem. 14, 707-718 (1999).

9. Skjemstad, J. O., Fitzpatrick, R. W., Zarcinas, B. A. \& Thompson, C. H. Genesis of Podzols on coastal dunes in Southern Queensland. II. Geochemistry and forms of elements as deduced from various soil extraction procedures. Aust. J. Soil Res. 30, 615-644 (1992).

10. Young, A. W., Campbell, A. S. \& Walker, T. W. Allophane isolated from a podsol developed on a non-vitric parent material. Nature 284, 46-48 (1980).

11. Parfitt, R. L., Hume, L. J. \& Sparling, G. P. Loss of availability of phosphate in New Zealand soils. J. Soil Sci. 40, 371-382 (1989).

12. Woignier, T. et al. The pesticide chlordecone is trapped in the tortuous mesoporosity of allophane clays. Environ. Sci. Pollut. Res. 25, 21350-21361 (2018).

13. Kramer, M. G., Sanderman, J., Chadwick, O. A., Chorover, J. \& Vitousek, P. M. Long-term carbon storage through retention of dissolved aromatic acids by reactive particles in soil. Glob. Change Biol. 18, 2594-2605 (2012).

14. Basile-Doelsch, I. et al. Mineral control of carbon pools in a volcanic soil horizon. Geoderma 137, 477-489 (2007).

15. Filimonova, S., Kaufhold, S., Wagner, F. E., Häusler, W. \& Kögel-Knabner, I. The role of allophane nano-structure and Fe oxide speciation for hosting soil organic matter in an allophanic Andosol. Geochim. Cosmochim. Acta 180, 284-302 (2016).

16. Allison, S. D. Soil minerals and humic acids alter enzyme stability: Implications for ecosystem processes. Biogeochemistry 81, 361-373 (2006).

17. Menezes-Blackburn, D. et al. Activity stabilization of Aspergillus niger and Escherichia coli phytases immobilized on allophanic synthetic compounds and montmorillonite nanoclays. Bioresour. Technol. 102, 9360-9367 (2011).

18. Baldermann, A. et al. Removal of barium, cobalt, strontium, and zinc from solution by natural and synthetic allophane adsorbents. Geosci. Switz. 8, 309 (2018).

19. Clarke, C. J. \& McBride, M. B. Chemisorption of $\mathrm{Cu}(\mathrm{II})$ and $\mathrm{Co}(\mathrm{II})$ on allophane and imogolite. Clays Clay Miner. 32, 300-310 (1984).

20. Jara, A. A., Violante, A., Pigna, M. \& de la Luz Mora, M. Mutual interactions of sulfate, oxalate, citrate, and phosphate on synthetic and natural allophanes. Soil Sci. Soc. Am. J. 70, 337 (2006).

21. Henmi, T. \& Wada, K. Morphology and composition of allophane. Am. Mineral. 61, 379-390 (1976).

22. Wada, S.-I. \& Wada, K. Visualization of the hollowness in unit particles of allophane and imogolite. J. Fac. Agric. Kyushu Univ. 59, 369-372 (2014).

23. Cradwick, P. D. G. et al. Imogolite, a hydrated aluminum silicate of tubular structure. Nat. Phys. Sci. 240, 187-189 (1972).

24. Barron, P. F., Wilson, M. A., Campbell, A. S. \& Frost, R. L. Detection of imogolite in soils using solid state ${ }^{29}$ Si NMR. Nature 299, 616-618 (1982).

25. Ackerman, W. C. et al. Gas/vapor adsorption in imogolite: A microporous tubular aluminosilicate. Langmuir 9, 1051-1057 (1993). 
26. Levard, C. \& Basile-Doelsch, I. Geology and mineralogy of imogolite-type materials. In Developments in Clay Science Vol. 7 (eds Yuan, P. et al.) 49-65 (Elsevier B.V., Amsterdam, 2016).

27. Clarke, C. J. \& McBride, M. B. Cation and anion retention by natural and synthetic allophane and imogolite. Clays Clay Miner. 32, 291-299 (1984).

28. Theng, B. K. G., Russell, M., Churchman, G. J. \& Parfitt, R. L. Surface properties of allophane, halloysite, and imogolite. Clays Clay Miner. 30, 143-149 (1982).

29. Ildefonse, P. et al. ${ }^{27} \mathrm{Al}$ MAS NMR and aluminum X-ray absorption near edge structure study of imogolite and allophanes. Clays Clay Miner. 42, 276-287 (1994).

30. Su, C., Harsh, J. B. \& Bertsch, P. M. Sodium and chloride sorption by imogolite and allophanes. Clays Clay Miner. 40, 280-286 (1992).

31. Childs, C. W., Parfitt, R. L. \& Newman, R. H. Structural studies of silica springs allophane. Clay Miner. 25, 329-341 (1990).

32. Creton, B., Bougeard, D., Smirnov, K. S., Guilment, J. \& Poncelet, O. Structural model and computer modeling study of allophane. J. Phys. Chem. C112, 358-364 (2008).

33. Levard, C. et al. Structure and distribution of allophanes, imogolite and proto-imogolite in volcanic soils. Geoderma 183-184, $100-108$ (2012).

34. Huang, P. M. Ionic factors affecting the formation of short-range ordered aluminosilicates. Soil Sci. Soc. Am. J. 55, 1172-1180 (1991).

35. Iyoda, F. et al. Synthesis and adsorption characteristics of hollow spherical allophane nano-particles. Appl. Clay Sci. 56, 77-83 (2012).

36. Ohashi, F., Wada, S.-I., Suzuki, M., Maeda, M. \& Tomura, S. Synthetic allophane from high-concentration solutions: Nanoengineering of the porous solid. Clay Miner. 37, 451-456 (2002).

37. Gunnarsson, I. \& Arnórsson, S. Amorphous silica solubility and the thermodynamic properties of $\mathrm{H}_{4} \mathrm{SiO}_{4}{ }^{\circ}$ in the range of 0 to $350^{\circ} \mathrm{C}$ at $\mathrm{P}_{\text {sat. }}$ Geochim. Cosmochim. Acta 64, 2295-2307 (2000).

38. Tobler, D. J., Shaw, S. \& Benning, L. G. Quantification of initial steps of nucleation and growth of silica nanoparticles: An in-situ SAXS and DLS study. Geochim. Cosmochim. Acta 73, 5377-5393 (2009).

39. Baumann, H. Polymerisation und depolymerisation der Kieselsäure unter verschiedenen bedingungen. Kolloid-Z. 162, 28-35 (1959).

40. Strekopytov, S., Jarry, E. \& Exley, C. Further insight into the mechanism of formation of hydroxyaluminosilicates. Polyhedron 25, 3399-3404 (2006).

41. Farmer, V. C., McHardy, W. J., Palmieri, F., Violante, A. \& Violante, P. Synthetic allophanes formed in calcareous environments: Nature, conditions of formation, and transformations. Soil Sci. Soc. Am. J. 55, 1162-1166 (1991)

42. Schneider, C., Doucet, F., Strekopytov, S. \& Exley, C. The solubility of an hydroxyaluminosilicate. Polyhedron 23, 3185-3191 (2004).

43. Wilson, M. A., McCarthy, S. A. \& Fredericks, P. M. Structure of poorly-ordered aluminosilicates. Clay Miner. 21, 879-897 (1986).

44. Du, P. et al. Insights into the formation mechanism of imogolite from a full-range observation of its sol-gel growth. Appl. Clay Sci. 150, 115-124 (2017).

45. Thill, A. From molecular precursor to imogolite nanotubes. In Developments in Clay Science Vol. 7 (eds Yuan, P. et al.) 429-457 (Elsevier B.V., Amsterdam, 2016).

46. Lippmaa, E., Magi, M., Samoson, A., Engelhard, G. \& Grimmer, A.-R. Structural studies of silicates by solid-state high-resolution 29Si NMR. J. Am. Chem. Soc. 102, 4889-4893 (1980).

47. Doucet, F. J. et al. The formation of hydroxyaluminosilicates of geochemical and biological significance. Geochim. Cosmochim. Acta 65, 2461-2467 (2001).

48. Yucelen, G. I. et al. Formation of single-walled aluminosilicate nanotubes from molecular precursors and curved nanoscale intermediates. J. Am. Chem. Soc. 133, 5397-5412 (2011).

49. Hiradate, S. Speciation of aluminum in soil environments: Application of NMR technique. Soil Sci. Plant Nutr. 50, 303-314 (2004).

50. Isobe, T., Watanabe, T., De La Caillerie, J. B. D., Legrand, A. P. \& Massiot, D. Solid-state ${ }^{1} \mathrm{H}$ and ${ }^{27} \mathrm{Al} \mathrm{NMR}$ studies of amorphous aluminum hydroxides. J. Colloid Interface Sci. 261, 320-324 (2003).

51. Goodman, B. A., Russell, J. D., Montez, B., Oldfield, E. \& Kirkpatrick, R. J. Structural studies of imogolite and allophanes by aluminum-27 and silicon-29 nuclear magnetic resonance spectroscopy. Phys. Chem. Miner. 12, 342-346 (1985).

52. Childs, C. W., Hayashi, S. \& Newman, R. H. Five-coordinate aluminum in allophane. Clays Clay Miner. 47, 64-69 (1999).

53. Bi, S., Wang, C., Cao, Q. \& Zhang, C. Studies on the mechanism of hydrolysis and polymerization of aluminum salts in aqueous solution: Correlations between the 'Core-links' model and 'Cage-like' Keggin- $\mathrm{Al}_{13}$ model. Coord. Chem. Rev. 248, 441-455 (2004).

54. Lukić, M. J., Wiedenbeck, E., Reiner, H. \& Gebauer, D. Chemical trigger toward phase separation in the aqueous Al(III) system revealed. Sci. Adv. 6, eaba6878 (2020).

55. Bishop, J. L. et al. Spectral and hydration properties of allophane and imogolite. Clays Clay Miner. 61, 57-74 (2013).

56. Farmer, V. C., Fraser, A. R. \& Tait, J. M. Characterization of the chemical structures of natural and synthetic aluminosilicate gels and sols by infrared spectroscopy. Geochim. Cosmochim. Acta 43, 1417-1420 (1979).

57. Montarges-Pelletier, E. et al. Synthetic allophane-like particles: Textural properties. Colloids Surf. Physicochem. Eng. Asp. 255, 1-10 (2005).

58. Kumara, C. K., Ng, W. J., Bandara, A. \& Weerasooriya, R. Nanogibbsite: Synthesis and characterization. J. Colloid Interface Sci. 352, 252-258 (2010).

59. Sing, K. S. W. Assessment of surface area by gas adsorption. In Adsorption by Powders and Porous Solids 2nd edn (eds Rouquerol, F. et al.) 237-268 (Academic Press, Oxford, 2014).

60. Rouquerol, F., Rouquerol, J., Sing, K. S. W., Maurin, G. \& Llewellyn, P. Introduction. In Adsorption by Powders and Porous Solids 2nd edn (eds Rouquerol, F. et al.) 1-24 (Academic Press, Oxford, 2014).

61. Wada, S.-I. \& Wada, K. Density and structure of allophane. Clay Min. 12, 289-298 (1977).

62. Garrido-Ramirez, E. G. et al. Catalytic wet peroxide oxidation of phenol over iron or copper oxide-supported allophane clay materials: Influence of catalyst $\mathrm{SiO}_{2} / \mathrm{Al}_{2} \mathrm{O}_{3}$ ratio. Microporous Mesoporous Mater. 162, 189-198 (2012).

63. Hietala, S. L., Smith, D. M., Golden, J. L. \& Brinker, C. J. Anomalously low surface area and density in the silica-alumina gel system. J. Am. Ceram. Soc. 72, 2354-2358 (1989).

64. Nakanishi, R., Wada, S.-I., Suzuki, M. \& Maeda, M. Heat-induced gelation of hydroxy-aluminosilicate synthesized by instantaneous mixing of sodium silicate and aluminum chloride. J. Fac. Agric. Kyushu Univ. 52, 147-151 (2007).

65. Abidin, Z., Matsue, N. \& Henmi, T. Differential formation of allophane and imogolite: Experimental and molecular orbital study. J. Comput. Aided Mater. Des. 14, 5-18 (2007).

66. Henmi, T., Tange, K., Minagawa, T. \& Yoshinaga, N. Effect of $\mathrm{SiO}_{2} / \mathrm{Al}_{2} \mathrm{O}_{3}$ ratio on the thermal reactions of allophane. II. Infrared and X-ray powder diffraction data. Clays Clay Miner. 29, 124-128 (1981).

67. Clausen, L. \& Fabricius, I. BET measurements: Outgassing of minerals. J. Colloid Interface Sci. 227, 7-15 (2000).

68. Kaiser, K. \& Guggenberger, G. Mineral surfaces and soil organic matter. Eur. J. Soil Sci. 54, 219-236 (2003).

69. Du, P. et al. Calcination-induced changes in structure, morphology, and porosity of allophane. Appl. Clay Sci. 158, 211-218 (2018).

70. Vandickelen, R., De Roy, G. \& Vansant, E. F. New Zealand allophanes: A structural study. J. Chem. Soc. Faraday Trans. Phys. Chem. Condens. Phases 76, 2542-2551 (1980). 
71. Hofmann, A. et al. Characterization of the pores in hydrous ferric oxide aggregates formed by freezing and thawing. J. Colloid Interface Sci. 271, 163-173 (2004).

72. Asthana, R. \& Tewari, S. N. The engulfment of foreign particles by a freezing interface. J. Mater. Sci. 28, 5414-5425 (1993).

73. Peppin, S. S. L., Elliott, J. A. W. \& Worster, M. G. Solidification of colloidal suspensions. J. Fluid Mech. 554, 147-166 (2006).

74. Anderson, A. M. \& Worster, M. G. Periodic ice banding in freezing colloidal dispersions. Langmuir 28, 16512-16523 (2012).

75. Spannuth, M., Mochrie, S. G. J., Peppin, S. S. L. \& Wettlaufer, J. S. Particle-scale structure in frozen colloidal suspensions from small-angle X-ray scattering. Phys. Rev. E Stat. Nonlinear Soft Matter Phys. 83, 021402 (2011).

76. Jähnert, S. et al. Melting and freezing of water in cylindrical silica nanopores. Phys. Chem. Chem. Phys. 10, 6039-6051 (2008).

77. Zelenka, T. Adsorption and desorption of nitrogen at $77 \mathrm{~K}$ on micro- and meso-porous materials: Study of transport kinetics. Microporous Mesoporous Mater. 227, 202-209 (2016).

78. Pyman, M. A. F. \& Posner, A. M. The surface areas of amorphous mixed oxides and their relation to potentiometric titration. J. Colloid Interface Sci. 66, 85-94 (1978).

79. Wells, N. \& Childs, C. W. Flow behaviour of allophane and ferrihydrite under shearing forces. Aust. J. Soil Res. 26, 145-152 (1988).

80. Kaufhold, S. et al. Allophane compared with other sorbent minerals for the removal of fluoride from water with particular focus on a mineable Ecuadorian allophane. Appl. Clay Sci. 50, 25-33 (2010).

81. Henmi, T., Nakai, M., Seki, T. \& Yoshinaga, N. Structural changes of allophanes during dry grinding: dependence on $\mathrm{SiO}_{2} / \mathrm{Al}_{2} \mathrm{O}_{3}$ ratio. Clay Miner. 18, 101-107 (1983).

82. Katiyar, N. K., Biswas, K. \& Tiwary, C. S. Cryomilling as environmentally friendly synthesis route to prepare nanomaterials. Int. Mater. Rev. https://doi.org/10.1080/09506608.2020.1825175 (2020).

83. Sing, K. S. W., Rouquerol, F., Rouquerol, J. \& Llewellyn, P. Assessment of mesoporosity. In Adsorption by Powders and Porous Solids 2nd edn (eds Rouquerol, F. et al.) 269-302 (Academic Press, Oxford, 2014).

84. Mackenzie, K. J. D., Bowden, M. E. \& Meinhold, R. H. The structure and thermal transformations of allophanes studied by ${ }^{29} \mathrm{Si}$ and ${ }^{27} \mathrm{Al}$ high resolution solid-state NMR. Clays Clay Miner. 39, 337-346 (1991).

85. Aomine, S. \& Otsuka, H. Surface of soil allophanic clays. Trans. 9th Int. Congr. Soil Sci. 1, 731-737 (1968).

86. Kaufhold, S. et al. A new massive deposit of allophane raw material in Ecuador. Clays Clay Miner. 57, $72-81$ (2009).

87. Paterson, E. Specific surface area and pore structure of allophanic soil clays. Clay Miner. 12, 1-9 (1977).

88. Chevallier, T., Woignier, T., Toucet, J., Blanchart, E. \& Dieudonné, P. Fractal structure in natural gels: Effect on carbon sequestration in volcanic soils. J. Sol-Gel Sci. Technol. 48, 231-238 (2008).

89. Pereira, R. C. et al. Assessing the pore structure and surface area of allophane-rich and non-allophanic topsoils by supercritical drying and chemical treatment. Geoderma 337, 805-811 (2019).

90. Woignier, T., Primera, J., Duffours, L., Dieudonné, P. \& Raada, A. Preservation of the allophanic soils structure by supercritical drying. Microporous Mesoporous Mater. 109, 370-375 (2008).

91. Inagaki, T. M., Mueller, C. W., Lehmann, J. \& Kögel-Knabner, I. Andosol clay re-aggregation observed at the microscale during physical organic matter fractionation. J. Plant Nutr. Soil Sci. 182, 145-148 (2019).

92. Kubota, T. Aggregate-formation of allophanic soils: Effect of drying on the dispersion of the soils. Soil Sci. Plant Nutr. 18, 79-97 (1972).

93. Karube, J. \& Abe, Y. Water retention by colloidal allophane and imogolite with different charges. Clays Clay Miner. 46, 322-329 (1998).

94. Rousseaux, J. M. \& Warkentin, B. P. Surface properties and forces holding water in allophane soils. Soil Sci. Soc. Am. J. 40, 446-451 (1976).

95. Jongmans, A. G., Denaix, L., Van Oort, F. \& Nieuwenhuyse, A. Induration of C horizons by allophane and imogolite in Costa Rican volcanic soils. Soil Sci. Soc. Am. J. 64, 254-262 (2000).

96. Farmer, V. C., Fraser, A. R., Robertson, L. \& Sleeman, J. R. Proto-imogolite allophane in podzol concretions in Australia: Possible relationship to aluminous ferrallitic (lateritic) cementation. J. Soil Sci. 35, 333-340 (1984).

97. Thompson, C. H., Bridges, E. M. \& Jenkins, D. A. Pans in humus podzols (Humods and Aquods) in coastal southern Queensland. Aust. J. Soil Res. 34, 161-182 (1996).

98. Knight, C. T. G. \& Kinrade, S. D. A primer on the aqueous chemistry of silicon. In Silicon in Agriculture Vol. 8 (eds Datnoff, L. E. et al.) 57-84 (Elsevier, Amsterdam, 2001).

\section{Acknowledgements}

This work was funded by the Deutsche Forschungsgemeinschaft (RE 2251/9-1). We thank Dr. Dörte Diehl and Prof. Gabriele Schaumann (Universität Koblenz-Landau), Mathias Stein (Universität Hohenheim), Jana Dobritzsch, Dr. Klaus Kaiser and Prof. Robert Mikutta (Martin-Luther-Universität Halle-Wittenberg) for enabling the BET analyses. We greatfully acknowledge the contribution of the ESEM images by Dr. Christian Buchmann (Universität Koblenz-Landau). We thank Prof. Henry Strasdeit and Hannes Pleyer (Universität Hohenheim) for enabling FTIR analyses, and Detlev Frobel and Dr. Ludger Herrmann for support in XRD analyses.

\section{Author contributions}

K.R.L. performed the experimental work. K.R.L. and T.R. designed the synthesis protocol. H.B. and G.B. conducted the ${ }^{29} \mathrm{Si}$ and ${ }^{27} \mathrm{Al}$ NMR spectroscopy measurements and contributed to data analysis. E.R. and M.W. conducted TEM measurements. K.R.L. wrote the manuscript with contributions of all authors.

\section{Funding}

Open Access funding enabled and organized by ProjektDEAL

\section{Competing interests}

The authors declare no competing interests.

\section{Additional information}

Supplementary Information The online version contains supplementary material available at https://doi.org/ 10.1038/s41598-021-83643-w.

Correspondence and requests for materials should be addressed to K.R.L.

Reprints and permissions information is available at www.nature.com/reprints. 
Publisher's note Springer Nature remains neutral with regard to jurisdictional claims in published maps and institutional affiliations.

(c) (i) Open Access This article is licensed under a Creative Commons Attribution 4.0 International License, which permits use, sharing, adaptation, distribution and reproduction in any medium or format, as long as you give appropriate credit to the original author(s) and the source, provide a link to the Creative Commons licence, and indicate if changes were made. The images or other third party material in this article are included in the article's Creative Commons licence, unless indicated otherwise in a credit line to the material. If material is not included in the article's Creative Commons licence and your intended use is not permitted by statutory regulation or exceeds the permitted use, you will need to obtain permission directly from the copyright holder. To view a copy of this licence, visit http://creativecommons.org/licenses/by/4.0/.

(C) The Author(s) 2021 